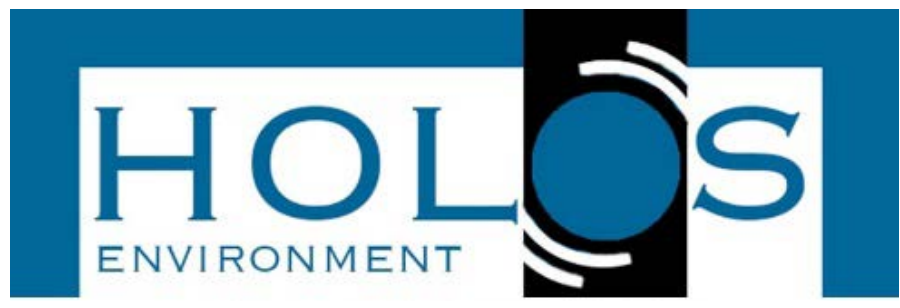

\title{
EFEITOS DA IMPLANTAÇÃO E OPERAÇÃO DO COMPLEXO MINERÁRIO DO SISTEMA MINAS-RIO NA QUALIDADE DAS ÁGUAS SUPERFICIAIS
}

\section{EFFECTS OF THE INSTALLATION AND OPERATION OF THE MINAS-RIO SYSTEM MINING COMPLEX ON SURFACE WATER QUALITY}

\author{
Gabriela Santos Oliveira $^{1}$; Adriana Alves Pereira ${ }^{1}$
}

Artigo recebido em: 16/08/2018 e aceito para publicação em: 04/02/2019.

DOI: http://dx.doi.org/10.14295/holos.v19i1.12306

Resumo: Diversos são os impactos ambientais causados por atividades de mineração e beneficiamento de minério de ferro. No caso específico da mineração do Sistema Minas-Rio, localizada no município de Conceição do Mato Dentro, Minas Gerais, não há publicações a respeito da influência dessas atividades na qualidade das águas superficiais da região. Ao mesmo tempo, comunidades do entorno demonstram preocupações relacionadas ao comprometimento dos diversos usos dessas águas. Este artigo objetivou analisar o efeito da implantação e operação desse complexo minerário na qualidade das águas superficiais das sub-bacias do entorno, bem como o atendimento dos parâmetros de qualidade da água aos padrões ambientais legais. Foram analisados dados de monitoramento (médias mensais) referentes aos períodos anterior $(2006,2007)$ e posterior (2010 a 2016) à implantação e operação do empreendimento para os seguintes parâmetros: $\mathrm{pH}$, sólidos dissolvidos totais, sólidos suspensos totais, turbidez, ferro total, manganês total, DBO, chumbo total, mercúrio total e coliformes termotolerantes. O efeito do local (sub-bacias do Córrego Passa Sete, do Ribeirão Folheta e do Rio Santo Antônio) e do período de coleta de amostras (anterior x posterior) foram testados (Testes de Kruskal-Wallis e Mann-Whitney). Relações entre as variáveis foram testadas através da correlação de Spearman. Conclui-se que as atividades de implantação e operação do complexo minerário contribuíram para aumentar os níveis de $\mathrm{pH}$, sólidos dissolvidos totais, sólidos suspensos totais, turbidez, ferro total e manganês total nos corpos hídricos do entorno (sub-bacia do Córrego Passa Sete). Os parâmetros turbidez, manganês total, DBO e coliformes termotolerantes mostraram resultados maiores que os limites legais, indicando não adequação da qualidade das águas da região a diversos usos.

Palavras-chave: Mineração de ferro. Causa e efeito. Poluição da água. Recursos hídricos.

Abstract: Iron ore mining and beneficiation cause many environmental impacts. In the specific case of the mining site called Minas-Rio System, located at Conceição do Mato Dentro city, Minas Gerais, there is a lack of publications related to the influence of these activities in the superficial water quality of the region. At the same time, nearby communities are concerned about the implications to the various uses of water. This article aimed to analyze the effect of the installation and operation of this mining complex on the superficial water quality from the surrounding hydrographic sub-basin, as well as the compliance of water quality parameters with environmental legal standards. It was analyzed monitoring data (monthly average) of the previous $(2006,2007)$ and posterior (2010 to 2016) periods to the installation and operation of the enterprise to the following parameters: $\mathrm{pH}$, total dissolved solids, total suspended solids, turbidity, total iron, total manganese, BOD, total lead, total mercury and thermotolerant coliforms. The effect of the location (sub-basin of Passa Sete Creek, of Folheta Riverside and of Santo Antônio River) and of the period of sampling (previous x posterior) were tested (Kruskal-Wallis and Mann-Whitney Tests). Relationship among the variables were tested through

${ }^{1}$ Centro Federal de Educação Tecnológica de Minas Gerais (CEFET-MG). E-mails: gabrielasts.oliveira@gmail.com, adrianaw@cefetmg.br 
Spearman correlation. The conclusion is that the activities of installation and operation of the mining complex contributed to increase the levels of $\mathrm{pH}$, total dissolved solids, total suspended solids, turbidity, total iron and total manganese at the nearby water bodies (sub-basin of Passa Sete Creek). The parameters turbidity, total manganese, BOD and thermotolerant coliforms showed results above the legal limits, indicating that the water quality of the region is not suitable to several uses.

Palavras-chave: Iron ore mining. Cause and effect. Water pollution. Water resources.

\section{INTRODUÇÃO}

O Brasil é um dos maiores produtores e exportadores de minérios do mundo. Em Minas gerais, a indústria extrativista mineral corresponde a $8 \%$ de todo o PIB e emprega cerca de 60.000 pessoas. O minério de ferro, carro chefe da produção mineral do Estado, corresponde a $66 \%$ da produção brasileira (INSTITUTO BRASILEIRO DE MINERAÇÃO, 2015). Apesar dos benefícios socioeconômicos que esta atividade traz, como geração de empregos, aumento da arrecadação de impostos no município, movimentação da economia e desenvolvimento local, há que se considerar, também, que a lavra e processamento de minério gera impactos ao meio ambiente (LOPES e RUCHKYS, 2015; GUIMARÃES e MILANEZ, 2017). Em se tratando de impactos sobre a qualidade das águas superficiais, tem-se o possível aumento da turbidez e, até mesmo, o assoreamento de corpos d'água próximos aos empreendimentos minerários (MECHI e SANCHES, 2010; SILVA e ANDRADE, 2017). Este fenômeno se deve principalmente à supressão da vegetação e à remoção da camada superficial do solo, práticas necessárias à lavra a céu aberto, mas que aumentam a erodibilidade do solo (KATPATAL et al., 2017). Os sedimentos carreados para os corpos d'água podem conter metais pesados e substâncias tóxicas (SALOMONS, 1995; GALHARDI e SOLDERA, 2018), trazendo risco ao ecossistema aquático e à população que usufrui do recurso hídrico contaminado. Há, portanto, a necessidade do monitoramento da qualidade dos corpos hídricos próximos a empreendimentos minerários.

Poucos estudos analisaram a influência das atividades de mineração de ferro na qualidade das águas superficiais no estado de Minas Gerais (COSTA et al., 2003; VON SPERLING et al., 2004; PEREIRA et al., 2008; RODRIGUES et al., 2014). O complexo minerário do Sistema Minas-Rio, localizado na sub-bacia do Rio Santo Antônio, afluente do Rio Doce, constitui em uma importante atividade econômica na região do município de Conceição do Mato Dentro. Para o desenvolvimento das ati- 
vidades de extração e beneficiamento de minério de ferro, a água é um importante insumo utilizado, cujos efluentes, após tratamento, são direcionados aos recursos hídricos localizados no entorno. Os corpos hídricos desta região são de suma importância para as comunidades locais, uma vez que suas águas são usadas para abastecimento doméstico, dessedentação de animais, recreação, lazer, além do uso na agroindústria e como meio para escoamento de efluentes sanitários (BRANDT MEIO AMBIENTE, 2007). Apesar de haver uma preocupação relacionada aos diversos impactos que esse empreendimento causa na região, inclusive nos corpos dágua superficiais (GUEDES, 2014; GODINHO et al., 2016), existe uma escassez de estudos científicos que reportem e analisem dados de qualidade dessas águas. Dessa forma, o objetivo deste trabalho foi avaliar os efeitos da implantação e operação das atividades de mineração e beneficiamento de minério de ferro na qualidade das águas superficiais em seu entorno. Além disto, foi verificado o atendimento aos padrões ambientais legais, de modo a analisar a adequação da qualidade das águas aos seus diversos usos.

\section{MATERIAL E MÉTODOS}

\subsection{Caracterização da área de estudo}

A área de estudo compreende os corpos lóticos adjacentes ao complexo minerário do Sistema Minas-Rio, nos quais foram realizadas campanhas de monitoramento da qualidade das águas, tanto anteriormente quanto posteriormente à implantação do empreendimento e durante sua operação. Este empreendimento realiza a extração e beneficiamento de minério de ferro, e localiza-se na zona rural dos municípios de Conceição do Mato Dentro e Alvorada de Minas, situados na bacia federal do Rio Doce, no estado de Minas Gerais.

A implantação do complexo minerário do Sistema Minas-Rio vem ocorrendo em etapas. A Figura 1 apresenta o cronograma de implantação e operação das denominadas Etapa 1 e Etapa 2 do empreendimento, bem como os períodos em que campanhas de monitoramento da qualidade das águas foram realizadas, tanto antes do início da implantação do empreendimento, quanto posteriormente.

A Etapa 1 abrange as seguintes estruturas: cava (Mina do Sapo), usina de beneficiamento, barragem de rejeitos, pilha de estéril e dique de contenção de rejei- 
tos, denominado Dique 1. A implantação da Etapa 1 iniciou-se em dezembro de 2009 e sua operação começou em outubro de 2014 (Figura 1). A Etapa 2 do empreendimento consistiu na ampliação das frentes de lavra da Mina do Sapo e da pilha de estéril, na implantação de um novo dique de contenção, denominado Dique 2, e de um novo sistema de reutilização de água recuperada da barragem de rejeitos com uma subestação elétrica. A Etapa 2 começou a ser implantada em outubro de 2015 e sua operação iniciou-se um ano depois (FERREIRA ROCHA, 2014). As licenças prévia e de instalação para a Etapa 3, que prevê a expansão da cava da direção sul, foram obtidas em dezembro de 2017. Monitoramentos referentes a essa etapa não foram incluídos no presente estudo.

Figura 1 - Representação das campanhas de monitoramento da qualidade das águas e cronogramas de implantação e operação das etapas 1 e 2 do empreendimento minerário do Sistema Minas-Rio

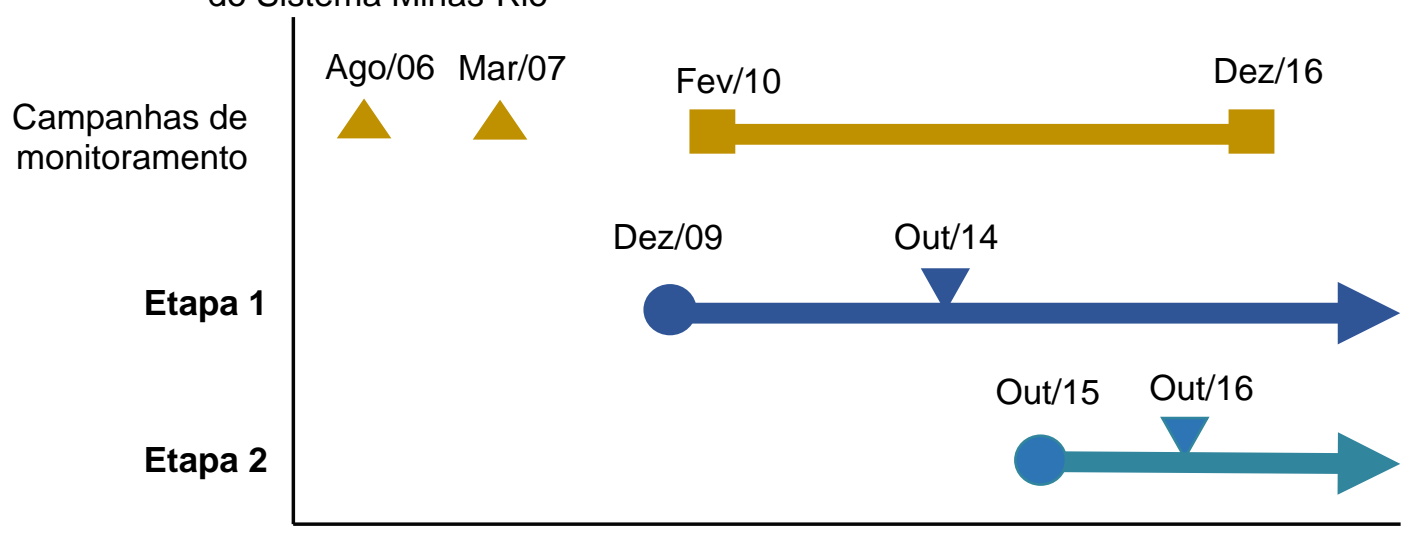

\section{Legenda}

Início da implantação

$\nabla$ Início das operações

Campanhas anteriores à implantação

Início/fim dos dados de monitoramento

O complexo minerário se insere no em uma área de transição entre os biomas Mata Atlântica e Cerrado. O clima da região é caracterizado como "subquente, semiúmido e tropical", com temperaturas médias inferiores a $23,5^{\circ}$ ao longo do ano, e baixa amplitude térmica. A distribuição dos índices pluviométricos é irregular ao longo do ano, com precipitações mais elevadas no período de outubro a março e período seco entre abril e setembro. A base da economia das comunidades situadas no entorno do empreendimento é a agropecuária. Os pastos nativos constituem em grande parcela de cobertura do solo, dividindo espaço com significativas manchas 
de matas preservadas, além de capoeiras e pequenos cultivos. A maior parte dos esgotos provenientes das comunidades é destinada a fossas sépticas ou é diretamente lançada em corpos d'água da região, comprometendo sua qualidade (FERREIRA ROCHA, 2015).

\subsubsection{Processo de extração e beneficiamento de minério de ferro}

O método de lavra utilizado no Sistema Minas-Rio é a céu aberto. O minério extraído passa primeiramente pelo processo à seco, no qual é cominuído através das britagens primária e secundária e britador de rolos de alta pressão (Figura 2). O minério passa então pelo processo à úmido, o qual conta com água proveniente do Rio do Peixe e com a água recuperada do processo, para ser cominuído na moagem primária e concentrado na flotação, separando-se do rejeito (Figura 2). O rejeito é encaminhado, após espessamento, para a barragem de rejeitos, onde ocorre a sedimentação e adensamento dos sólidos, por gravidade. O efluente, após estes tratamentos, é vertido por extravasamento para o Córrego Passa Sete, afluente do Rio do Peixe. Na flotação, para promover a concentração do minério de ferro, são adicionados amido gelatinizado, amina, soda cáustica (para correção de pH) e água. O minério concentrado é direcionado para a remoagem e segue para o espessador de concentrado (Figura 2), onde recebe adição de $\mathrm{CO}_{2}$, para correção do $\mathrm{pH}$, e de floculante para promover a sedimentação dos sólidos. A polpa de minério é então transportada, via mineroduto, até o Porto do Açu, no município de São João da Barra, estado do Rio de Janeiro, onde é filtrada, sendo o minério de ferro exportado.

\subsection{Locais de monitoramento e parâmetros de qualidade de água}

Os dados de qualidade das águas superficiais em 17 pontos de monitoramento anteriores ao início da implantação do complexo minerário do Sistema Minas-Rio foram obtidos no Estudo de Impacto Ambiental da Etapa 1 do empreendimento (BRANDT MEIO AMBIENTE, 2007). Esse monitoramento contou com duas campanhas, uma em agosto de 2006 (período de seca), e outra em março de 2007 (período chuvoso) (Figura 1), e consistem nos valores de background do presente estudo. Os resultados de monitoramento de qualidade de águas superficiais em 23 pontos de monitoramento posteriores à implantação do empreendimento foram obtidos nos 
relatórios do Programa de Gestão de Recursos Hídricos, apresentados pela empresa ao órgão ambiental licenciador, para cumprimento de condicionantes das licenças ambientais. As coletas ocorreram com uma frequência mínima trimestral entre os anos de 2010 e 2016 (Figura 1), totalizando em 26 campanhas de monitoramento. A Figura 3 mostra a localização do complexo minerário, da hidrografia da região, das sub-bacias que compreendem a área de estudo, denominadas zonas (Zona A: subbacia do Córrego Passa Sete; Zona B: Sub-bacia do Ribeirão Folheta; Zona C: Subbacia do Rio Santo Antônio), além da localização dos pontos de monitoramento da qualidade das águas superficiais, antes e após a implantação do complexo minerário.

Figura 2 - Fluxograma simplificado do processo de beneficiamento de minério de ferro do Sistema Minas-Rio

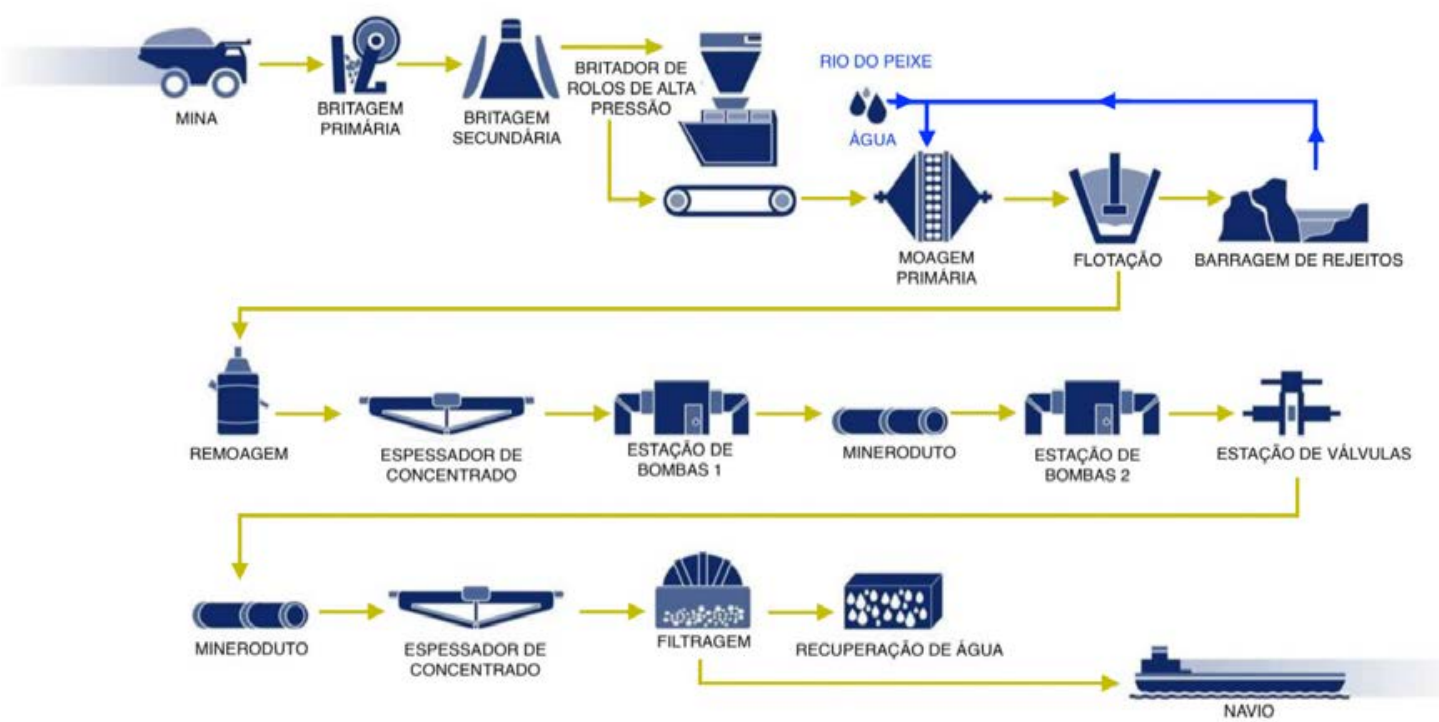

Os parâmetros de qualidade de água analisados foram: $\mathrm{pH}$, sólidos dissolvidos totais, sólidos suspensos totais, turbidez, ferro total, manganês total, demanda bioquímica de oxigênio (DBO), chumbo total, mercúrio total e coliformes termotolerantes. Dados diários de precipitação pluviométrica (em $\mathrm{mm}$ ) foram obtidos de um pluviômetro localizado na zona A (latitude: 668.278, longitude: 7.910.418, altitude: $696 \mathrm{~m})$, no período entre 25/02/2008 até 31/05/2016. 
Figura 3 - Pontos de monitoramento de águas superficiais anteriores e posteriores à implantação do complexo minerário do Sistema Minas-Rio. Zonas A, B e C correspondem às sub-bacias do Córrego Passa Sete, do Ribeirão Folheta e do Rio Santo Antônio, respectivamente

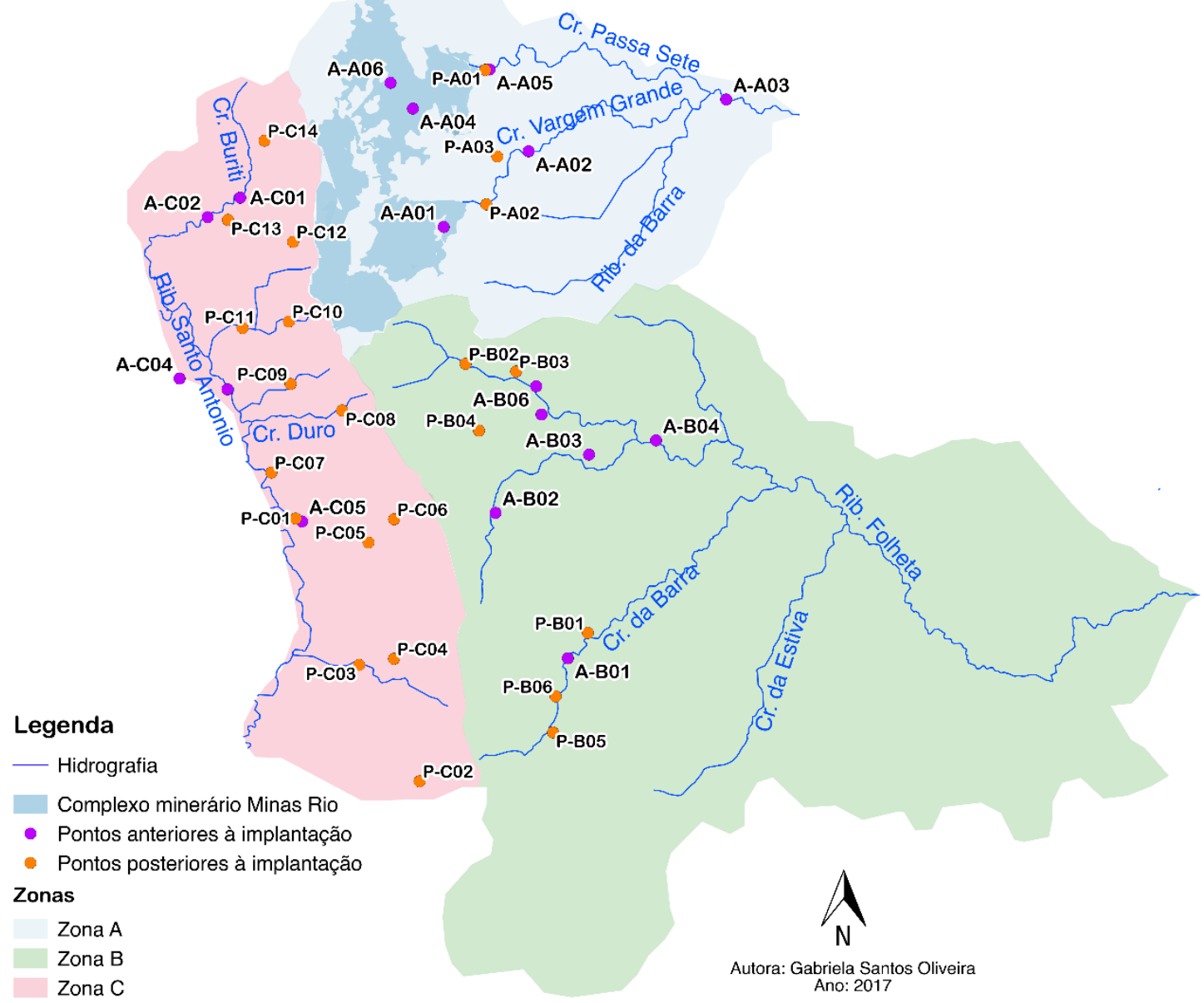

As amostragens foram realizadas de acordo com as diretrizes estabelecidas pela Associação Brasileira de Normas Técnicas (ABNT) previstas nas normas NBR 9897/1987 (ASSOCIAÇÃO BRASILEIRA DE NORMAS TÉCNICAS, 1987a) e NBR 9898/1987 (ASSOCIAÇÃO BRASILEIRA DE NORMAS TÉCNICAS, 1987b). As amostras foram coletadas na superfície da coluna d'água. Após a coleta, as amostras foram mantidas sob refrigeração e encaminhadas ao laboratório para análises. As análises foram realizadas de acordo com a versão mais recente do Standard Methods for the Examination of Water and Wastewater à época da elaboração de cada relatório (AMERICAN PUBLIC HEALTH ASSOCIATION, 2017).

\subsection{Análise dos dados}

Uma análise da estatística descritiva dos dados foi realizada para cada um 
dos parâmetros de qualidade da água analisados. Séries temporais das médias mensais de cada parâmetro nas três zonas de monitoramento foram analisadas quanto ao atendimento aos limites estabelecidos pela Resolução CONAMA $n^{\circ}$ 357/05 para águas superficiais de águas doces classe 2 (BRASIL, 2005).

Os efeitos do local de coleta das amostras (representado pelo grupo de pontos localizados nas zonas A, B e C) e do período de coleta (anterior e posterior à implantação do empreendimento, somente na zona A) foram testados. O período anterior refere-se às campanhas realizadas em ago/06 e mar/07, comparadas, respectivamente, com as campanhas realizadas entre junho, julho e agosto e entre janeiro, fevereiro e março, entre os anos de 2010 a 2016. Antes da análise estatística, testou-se a normalidade dos dados através do teste Kolmogorov-Smirnoff e a homogeneidade de variância através do teste Levene. Como a grande maioria das variáveis não apresentaram distribuição normal nem homogeneidade de variâncias entre os grupos, foram utilizados testes não paramétricos (Kruskal-Wallis e MannWhitney).

Para se obter informações sobre o comportamento ambiental das variáveis, foram determinados os graus de correlações entre as concentrações dos diversos parâmetros de qualidade de águas e precipitação pluviométrica do mês da coleta, para o período posterior à implantação do empreendimento, segundo o coeficiente de correlação de Spearman.

O nível de significância adotado foi de $5 \%$. Os testes foram realizados utilizando-se o Software IBM SPSS (Statistical Package SPSS version 22.0, Chicago, IL, USA). Resultados que se mostraram abaixo do limite de detecção foram considerados, para fins de análise estatística, com valores iguais à metade dos limites de detecção. Tais valores devem ser considerados nas análises estatísticas e não excluídos dela como se não existissem (UNITED STATES ENVIRONMENTAL PROTECTION AGENCY, 2006).

\section{RESULTADOS E DISCUSSÃO}

\subsection{Efeitos do local de coleta de amostras}

Os resultados dos testes de comparação não indicaram diferenças significativas entre as medianas de todos os parâmetros de qualidade de águas nos três lo- 
cais de monitoramento (zonas A, B e C) para o período anterior à implantação do empreendimento (teste Kruskal-Wallis, $p>0,05$ ). Isto indica que toda a região de estudo estava exposta a semelhantes condições ambientais antes da implantação das atividades de extração e beneficiamento de minério de ferro.

Entretanto, para o período posterior à implantação do empreendimento, diversos parâmetros apresentaram diferenças significativas entre as zonas de coleta $(\mathrm{pH}$, turbidez, sólidos dissolvidos totais, sólidos em suspensão totais, ferro total, manganês total e coliformes termotolerantes) (teste Kruskal-Wallis, $p<0,05$ ).

As Figuras 4, 5 e 6 apresentam os gráficos das séries das médias dos parâmetros de qualidade de água para cada local de coleta (zonas A, B e C), ao longo de todas as campanhas de monitoramento, realizadas anteriormente e posteriormente à implantação do empreendimento minerário. $\mathrm{O}$ pH médio das zonas de pontos de monitoramento manteve-se dentro dos limites impostos para corpos d'água Classe 2 pela Resolução CONAMA $n^{0} 357 / 2005$ durante quase todas as campanhas de monitoramento (Figura 4). A zona A cruzou o limite inferior duas vezes $(\mathrm{pH}=5,8 \mathrm{em}$ out/2013 e jun/14), e a zona B uma única vez ( $\mathrm{pH}=5,9$ em jun/15), assim como a zona $\mathrm{C}(\mathrm{pH}=5,46 \mathrm{em}$ abr/14). No período posterior à implantação do complexo minerário, foi verificado $\mathrm{pH}$ mais elevado nos corpos d água da zona $\mathrm{A}(\mathrm{Mdn}=6,9)$ do que na zona B $(M d n=6,6)$ e C $(M d n=6,6)$ (teste de Mann-Whitney, $p<0,05)$. Como a atividade minerária localiza-se na zona $A$, este resultado mostra que a implantação e operação das atividades de extração e beneficiamento de minério de ferro pode ter influenciado nos níveis de $\mathrm{pH}$ da sub-bacia em que está inserida. Pereira et al. (2006), ao estudarem uma lagoa costeira que recebe influência da mineração e processamento de minério de ferro, verificaram um aumento no $\mathrm{pH}$ ao longo dos anos. Os autores constataram que isso provavelmente ocorreu devido ao aporte de nutrientes advindos da mina, que naturalmente contém fósforo, e do processamento do minério, que utiliza aminas no beneficiamento.

As médias de sólidos dissolvidos totais das zonas de pontos de monitoramento mantiveram-se abaixo do limite legal (500 mg/l) durante todas as campanhas, exceto em de jan/14 na zona B (516 mg/l) (Figura 4). Não choveu no dia da coleta (08/01/14), bem como nos 5 dias que o antecederam, o que elimina a hipótese do carreamento de sólidos suspensos, e consequentemente aumento dos dissolvidos (teste de Spearman, $r=0,12, p<0,05$ ) provenientes da bacia hidrográfica. Foi observada maior concentração de sólidos dissolvidos na zona A (Mdn = 39,7 mg/l) que 
nas demais zonas (Zona B: Mdn = 15,0 mg/l; Zona C: Mdn = 18,0 mg/l) no período posterior à instalação do complexo minerário, evidenciando a influência das atividades de implantação e operação do empreendimento no teor desse parâmetro nas águas superficiais do entorno. A implantação da atividade minerária implicou em supressão de vegetação e remoção da camada de solo superficial, o que pode ter intensificado o carreamento de sedimentos para os corpos d'água, aumentando os níveis, de sólidos suspensos (KRISHNASWAMY et al. 2006; SEBASTIAN et al., 2017), e consequentemente, de sólidos dissolvidos. Além disso, na fase de operação, a concentração de sólidos dissolvidos nos corpos superficiais pode estar relacionada à concentração de íons do efluente do processo de beneficiamento do minério de ferro, como constatado por Pereira et al. (2008) ao estudarem os efeitos da mineração e processamento de minério de ferro sobre lagoas costeiras.

Foi registrado um valor médio elevado para o ferro total na zona $A$, em jan/11 (27 mg/l) (Figura 5). Esta campanha aconteceu na fase implantação da Etapa 1 do empreendimento minerário (Figura 1), e pode ter sido influenciada pela intensificação da erosão do solo devido às obras civis e remoção de cobertura vegetal, aliada à precipitação ocorrida no dia de coleta $(23 \mathrm{~mm})$, uma vez que a área de estudo está próxima do Quadrilátero Ferrífero, região que apresenta valores de background naturalmente elevados para ferro e manganês (COSTA et al., 2003; RODRIGUES et al., 2014). Salienta-se que o ferro total apresentou correlações significativas com os parâmetros sólidos em suspensão totais, turbidez e manganês total (teste de Spearman, $r=0,29, r=0,70$ e $r=0,69$, respectivamente, $p<0,05)$. Apesar do período de monitoramento do parâmetro ferro total ter se concentrado somente entre fev/10 e jul/11, ou seja, durante a implantação da Etapa 1 do complexo minerário, foi possível verificar a influência das atividades de instalação do empreendimento nas concentrações desse parâmetro, uma vez que seus níveis na zona $\mathrm{A}$ ( $\mathrm{Mdn}=2,2 \mathrm{mg} / \mathrm{l}$ ) foram superiores aos níveis na zona $B(M d n=0,85 \mathrm{mg} / \mathrm{l})$ e na zona $C(\mathrm{Mdn}=1,0$ mg/l) (teste de Mann-Whitney, $p<0,05$ ). 
Figura 4 - Séries temporais das médias dos parâmetros pH, sólidos dissolvidos totais e sólidos em suspensão em corpos d’água superficiais localizados na região do Sistema Minas Rio. Zonas A, B e C: grupos de locais de coleta de amostras. Linha sólida: limite da Resolução CONAMA n 357/05 (classe 2)

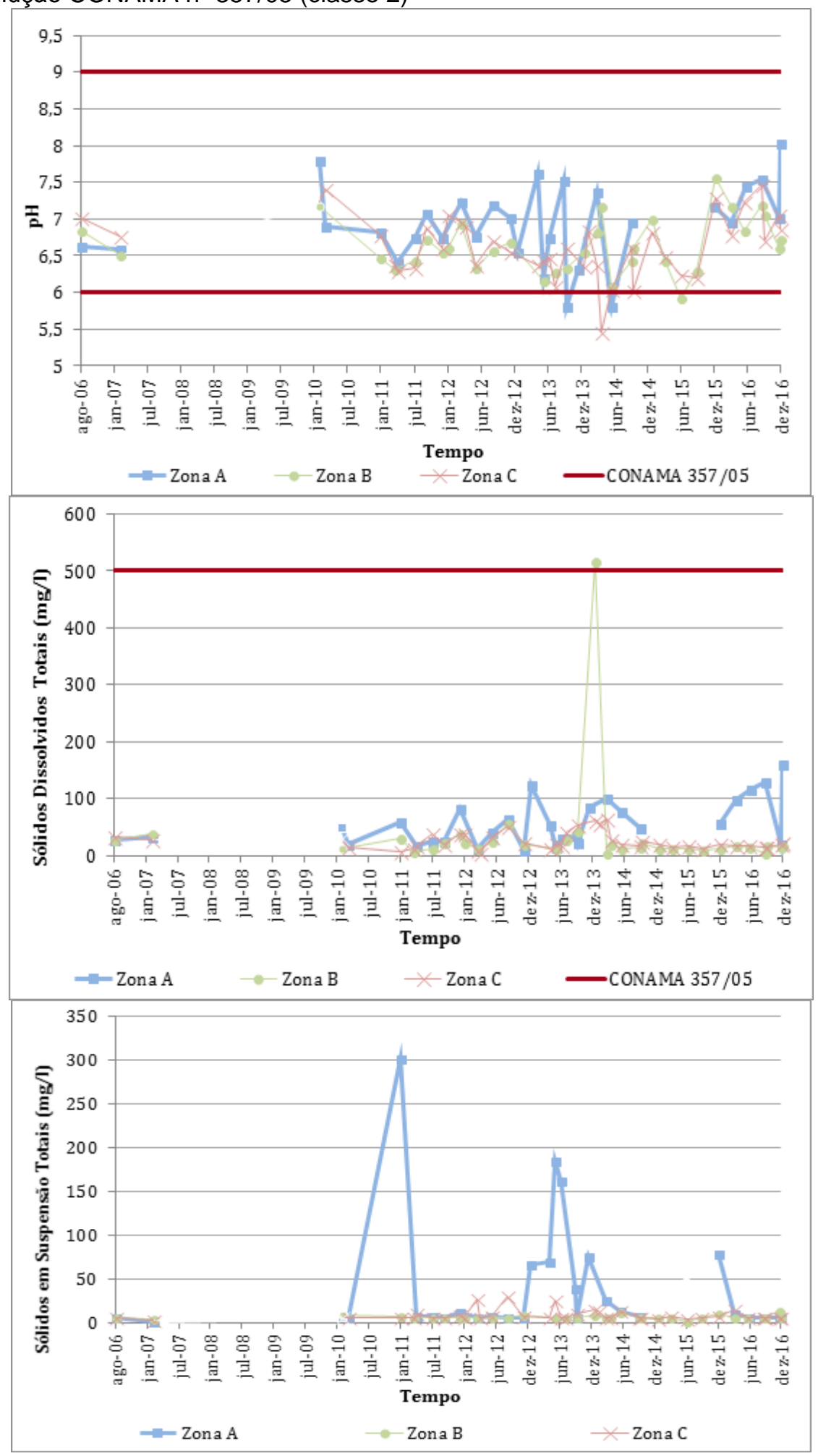


Figura 5 - Séries temporais das médias dos parâmetros turbidez, ferro total e manganês total em corpos d’água superficiais localizados na região do Sistema Minas Rio. Zonas A, B e C: grupos de locais de coleta de amostras. Linha sólida: limite da Resolução CONAMA n ${ }^{\circ}$ $357 / 05$ (classe 2)

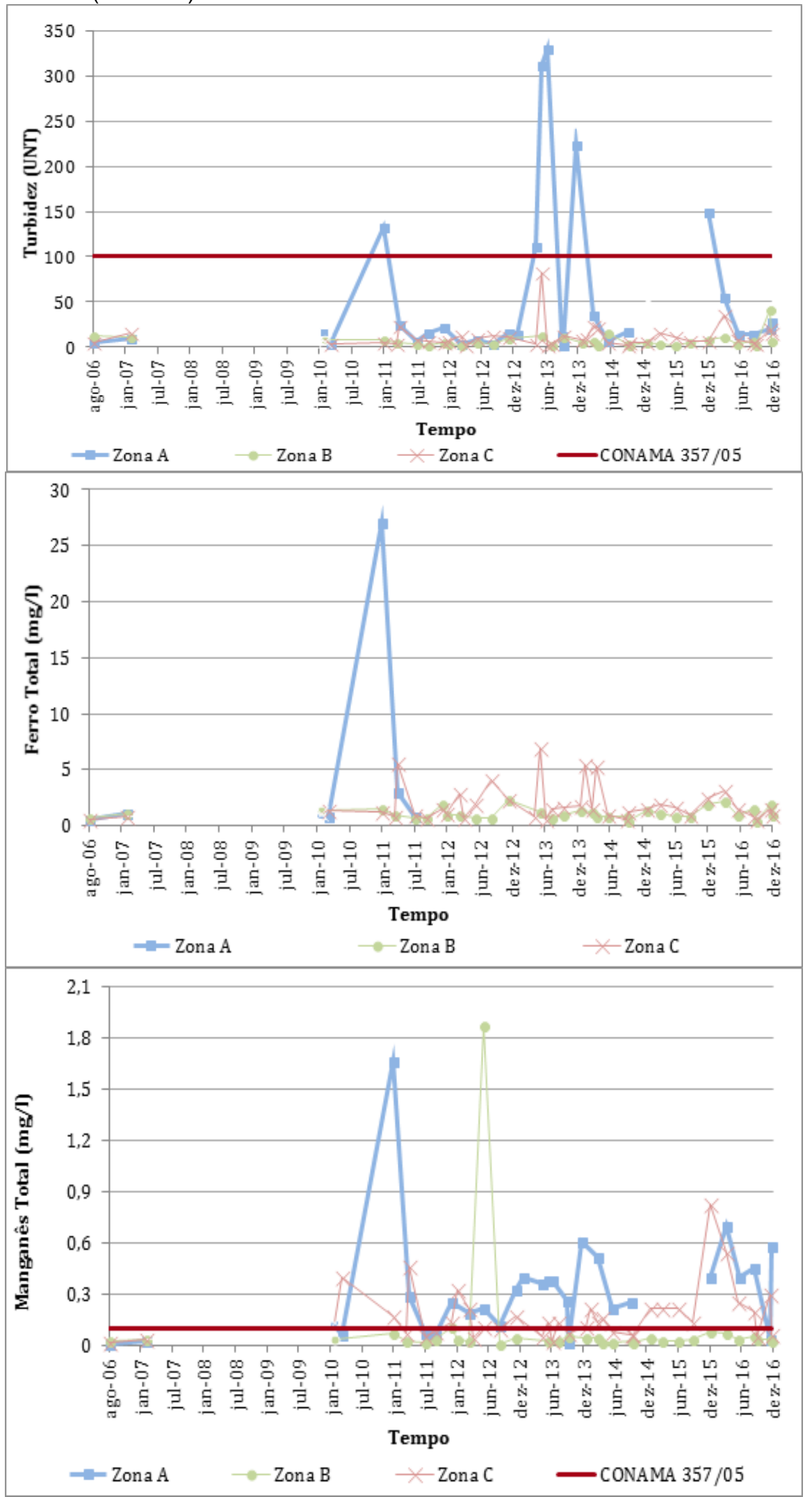


Figura 6 - Séries temporais das médias dos parâmetros DBO, chumbo total, mercúrio total e coliformes termotolerantes em corpos d'água superficiais localizados na região do Sistema Minas Rio. Zonas A, B e C: grupos de locais de coleta de amostras. Linha sólida: limite da Resolução CONAMA n ${ }^{\circ}$ 357/05 (classe 2)

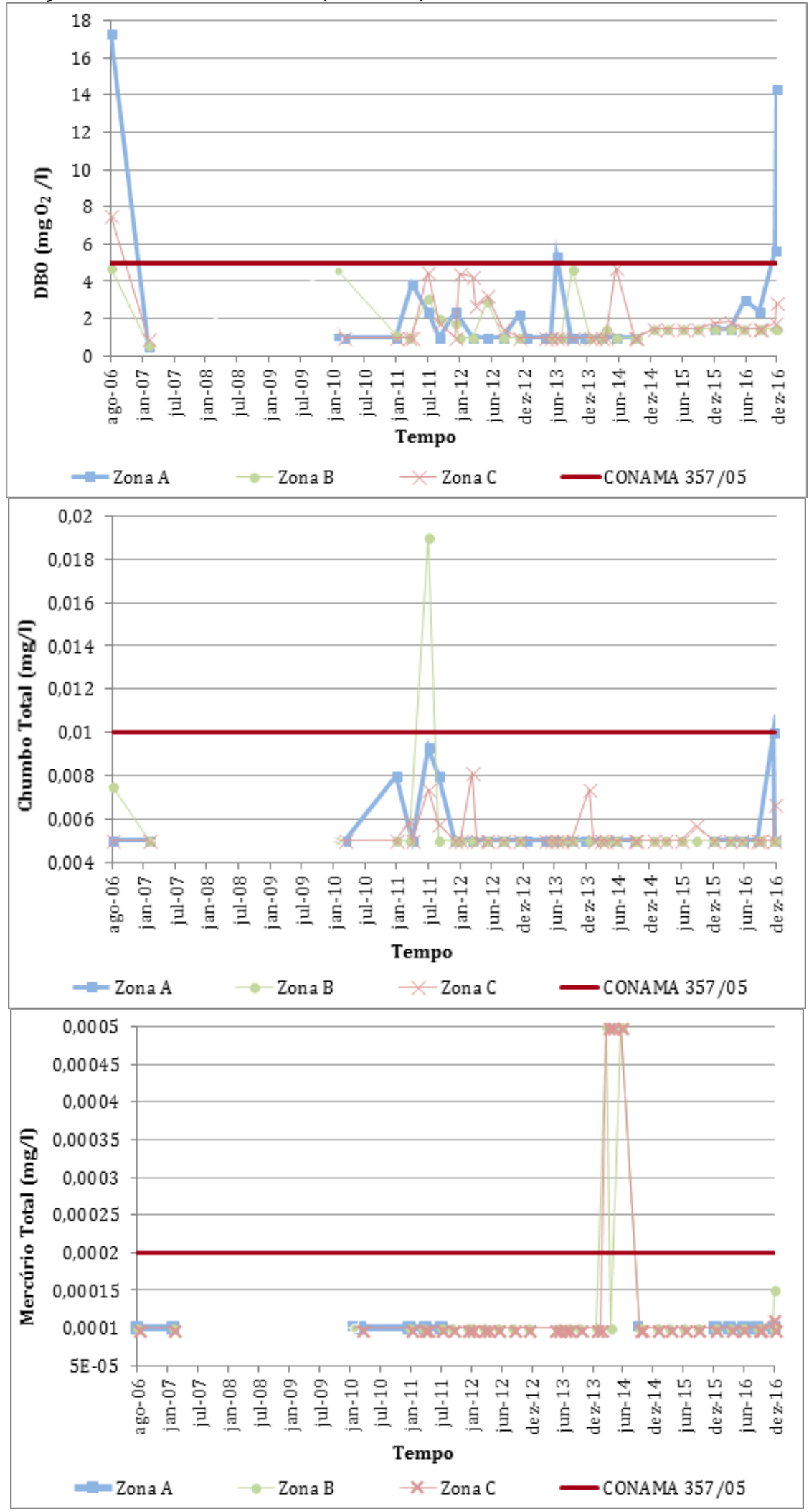

(continua) 
Figura 6 - Séries temporais das médias dos parâmetros DBO, chumbo total, mercúrio total e coliformes termotolerantes em corpos d'água superficiais localizados na região do Sistema Minas Rio. Zonas A, B e C: grupos de locais de coleta de amostras. Linha sólida: limite da Resolução CONAMA n ${ }^{\circ}$ 357/05 (classe 2) (conclusão)

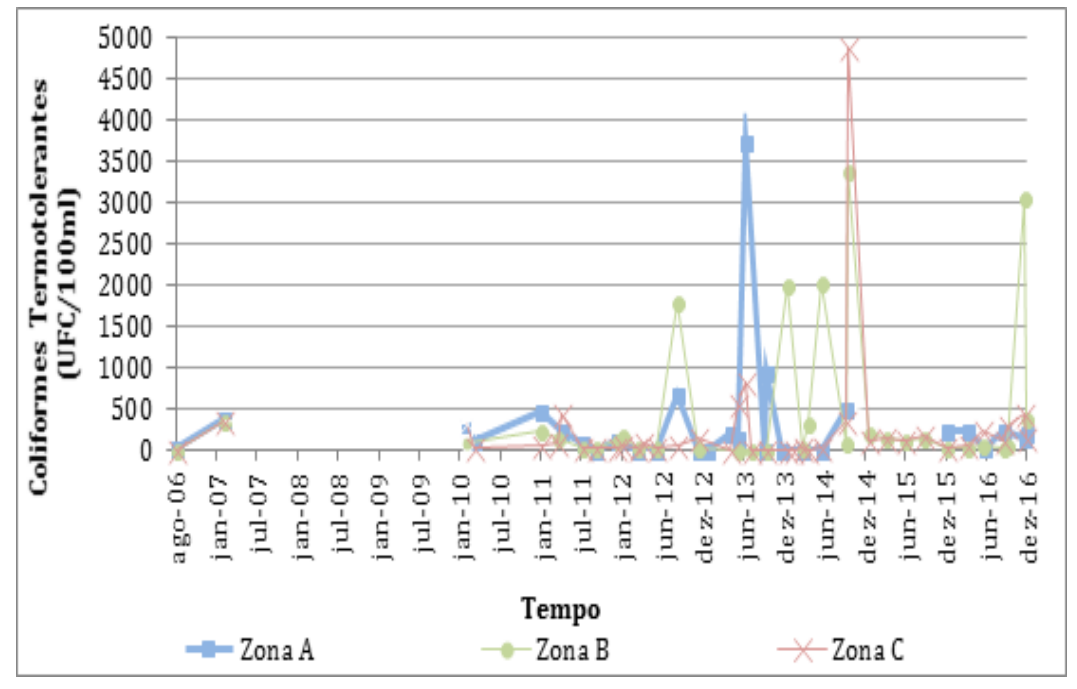

As concentrações médias de manganês total ultrapassaram o limite legal estabelecido pela Resolução CONAMA nº 357/05 para águas classe 2 (0,1 mg/l) em várias campanhas posteriores à implantação e operação das Etapas 1 e 2 do empreendimento minerário (Figura 1; Figura 5). Notam-se concentrações elevadas em relação às demais na campanha de jan/11 na zona $A(1,7 \mathrm{mg} / \mathrm{l})$ e na campanha de jun/12 na zona B (1,9 mg/l), ambas ocorridas na etapa de implantação da Etapa 1. Esse valor médio mais acentuado na zona $A$ ocorreu devido às altas concentrações, principalmente, no ponto P-A03 (3,5 mg/l), sendo que, como explicado anteriormente, no dia dessa campanha a precipitação foi de $23 \mathrm{~mm}$. Já o pico mais relevante da zona B ocorreu devido à alta concentração do ponto P-B02, sendo que no dia da campanha não houve chuva significativa, nem mesmo nos dias que o antecederam. Foram observadas concentrações de manganês total acima do limite legal não somente nas zonas A e B, mas também na zona C (Figura 5), indicando que, realmente, os valores background para esse parâmetro sejam naturalmente elevados na região de estudo. As concentrações de manganês total na zona A foram mais elevadas (Mdn = 0,23 mg/l) que nas demais zonas (Zona B: Mdn = 0,03mg/l; Zona C: Mdn $=0,06 \mathrm{mg} / \mathrm{l}$ ) (teste de Mann-Whitney, $\mathrm{p}<0,05)$ no período posterior à implantação do empreendimento. Isto indica que as atividades de implantação e operação do complexo minerário contribuíram para aumentar os níveis de manganês total nas águas da sub-bacia em que está inserido. Da mesma forma que o ferro total, o manganês 
total apresentou correlações significativas com os parâmetros sólidos em suspensão totais e turbidez (teste de Spearman, $r=0,33$ e $r=0,52$, respectivamente, $p<0,05$ ).

Resultados de DBO na área de estudo mostraram elevada variabilidade. $\mathrm{Na}$ $1^{\mathrm{a}}$ campanha de monitoramento anterior à implantação do empreendimento (ago/06), os valores médios de DBO foram altos, principalmente na zona A, que atingiu 17,3 mgO $2 / l$ (Figura 6). Após a implantação do empreendimento, e na região onde ele se localiza (zona A), verificaram-se resultados acima do limite da Resolução CONAMA n 357/05 na fase de implantação da Etapa 1 (jul/13: 5,4 mgO/l) na fase de operação das Etapas 1 e 2 (nov/16: 5,68 mgO $/ / \mathrm{le} \mathrm{dez/16:} \mathrm{14,3} \mathrm{mgO} / \mathrm{l}$ ) (Figura 1; Figura 6). Apesar desses resultados mais elevados, não foram observadas diferenças significativas nas concentrações de DBO entre as zonas de monitoramento posteriormente à implantação do empreendimento (teste de Kruskal-Wallis, p > 0,05). Apesar dos resultados não indicarem influência das atividades de mineração e beneficiamento de minério de ferro nas concentrações de DBO nos corpos hídricos adjacentes, é possível que esse efeito seja observado em monitoramentos posteriores à operação do empreendimento, uma vez que é adicionada matéria orgânica (amido e aminas) no processo de flotação. Em processo semelhante estudado por Pereira et al. (2006) foi reportado elevados níveis de DBO em águas superficiais que recebem efluentes proveniente do processo de concentração do minério de ferro. $\mathrm{Na}$ região de estudo, a mortandade de peixes do Córrego Passa Sete, registrada em junho de 2017 (PEREIRA et al., 2017), pode estar relacionada com elevados níveis de DBO nesse corpo hídrico.

Valor médio acima do limite legal para chumbo total $(0,01 \mathrm{mg} / \mathrm{l})$, foi registrado na campanha de jul/11 na zona B (0,019 mg/l) (Figura 6). Embora as concentrações médias de chumbo total tenham sido baixas no período posterior à implantação do complexo minerário (Figura 1; Figura 6), foram observados valores máximos acima do limite legal nas três zonas de estudo (zona A: 0,02 mg/l; zona B: 0,06 mg/l e zona C: 0,03 mg/l). Não foram observadas diferenças significativas nas concentrações de chumbo total entre as zonas de monitoramento posteriormente à implantação do empreendimento (teste de Kruskal-Wallis, $p>0,05$ ). Isto indica que a mineração não exerceu influência sobre a concentração de chumbo total nos corpos hídricos adjacentes. Constatação semelhante foi reportada por Pereira et al., (2008), em estudos realizados em uma mineração de ferro localizada no Quadrilátero Ferrífero. 
Concentrações de mercúrio total ficaram abaixo do limite de detecção durante quase todas as campanhas de monitoramento, exceto em mar/14 e jun/14, nas zonas B e C, que apresentam resultados acima do limite legal (0,0002 mg/l) (Figura 6). Não foram registrados resultados de mercúrio total na zona $A$ entre set/11 e set/15, com exceção da campanha realizada em set/14 (Figura 4). Devido à baixa variabilidade geral dos resultados, diferenças nas concentrações de mercúrio total entre as zonas de monitoramento no período posterior à implantação do empreendimento não foram observadas (teste de Kruskal-Wallis, $p>0,05$ ). Na região do Quadrilátero Ferrífero, próxima à área de estudo, a presença de mercúrio está associada à exploração de ouro, naturalmente presente com óxidos de manganês (WINDMOLLER et al., 2007) ou introduzido de forma antropogênica durante os séculos 18 e 19 (COSTA et al., 2003).

O parâmetro coliformes termotolerantes apresentou algumas concentrações elevadas em todas as zonas de coleta de amostras, em praticamente todo o período de monitoramento (Figura 6). Resultados médios mensais chegaram a 3.740 UFC/100ml na zona $A$ em jul/13, 3.400 UFC/100ml na zona $B$ em out/14 e 4.900 UFC/100ml zona $C$ também em out/14 (Figura 6), bem maiores que o limite legal de 1.000 UFC/100 ml (limite este baseado em amostras individuais coletadas bimestralmente). Não houve precipitação pluviométrica na maioria dos dias das coletas de amostras que apresentaram resultados individuais elevados, nem nos dias anteriores. Não foi possível evidenciar o efeito da implantação e operação das atividades minerárias no parâmetro coliformes termotolerantes, uma vez que as concentrações nas zonas A e B foram semelhantes e maiores que na zona $C$ (teste de MannWhitney, $p<0,05)$. O teor de coliformes termotolerantes está relacionado à contaminação fecal e, por isso, normalmente está vinculado com o despejo de efluentes sanitários ou excretas de aves e mamíferos (VON SPERLING, 2014). A empresa possui medidas de controle para os efluentes sanitários gerados, contando com 20 estações de tratamento (MDGEO, 2017).

\subsection{Efeitos do período de coleta de amostras}

Foram verificadas diferenças nas concentrações dos parâmetros sólidos suspensos totais, turbidez e manganês total nos períodos anterior e posterior à implantação do empreendimento na zona A (teste Mann-Whitney, $p<0,05$ ). 
Um aumento da concentração de sólidos suspensos totais nas águas superficiais foi verificada após a implantação do empreendimento, tanto nas campanhas de junho, julho e agosto (anterior: $\mathrm{Mdn}=5,0 \mathrm{mg} / \mathrm{l}$; posterior: $\mathrm{Mdn}=5,3 \mathrm{mg} / \mathrm{l}$ ) quanto nas campanhas de janeiro, fevereiro e março (anterior: $\mathrm{Mdn}=1,3 \mathrm{mg} / \mathrm{l}$; posterior: $\mathrm{Mdn}=$ 5,3 mg/l) (Teste Mann-Whitney, $p<0,05)$. Padrão semelhante foi verificado nos níveis de turbidez nos meses de junho, julho e agosto (anterior: Mdn = 5,4 UNT; posterior: $\mathrm{Mdn}=8,7 \mathrm{UNT}$ ) (Teste Mann-Whitney, $\mathrm{p}<0,05$ ). Apesar de não haver diferenças significativas entre os períodos de coleta para os meses de janeiro, fevereiro e março (teste de Mann-Whitney, $p>0,05$ ), também se verificou um aumento das medianas da turbidez no período posterior à implantação do complexo minerário (anterior: Mdn = 8,9 UNT; posterior: $\mathrm{Mdn}=11,9$ UNT).

Foi observado um aumento na concentração de manganês total após a implantação do empreendimento minerário tanto nos meses de janeiro, fevereiro e março (anterior: $\mathrm{Mdn}=0,03 \mathrm{mg} / \mathrm{l}$; posterior: $\mathrm{Mdn}=0,24 \mathrm{mg} / \mathrm{l}$ ), como nos meses de junho, julho e agosto (anterior: < 0,02 mg/l; posterior: $\mathrm{Mdn}=0,21 \mathrm{mg} / \mathrm{l})($ Teste de Mann-Whitney, $p<0,05)$.

Apesar dos parâmetros $\mathrm{pH}$, sólidos dissolvidos totais e ferro total não apresentarem diferenças significativas entre os períodos de coleta (Teste de MannWhitney, $p>0,05$ ), foi observado um aumento em suas medianas após a implantação do empreendimento minerário, tanto nos meses de janeiro, fevereiro e março (para pH: anterior: 6,6 e posterior: 7,0; para sólidos dissolvidos totais, anterior: $\mathrm{Mdn}$ = 33,0 mg/l e posterior: $M d n=44,8 \mathrm{mg} / \mathrm{l}$; para ferro total, anterior: $\mathrm{Mdn}=0,86 \mathrm{mg} / \mathrm{l} \mathrm{e}$ posterior: $\mathrm{Mdn}=0,92 \mathrm{mg} / \mathrm{l}$ ), quanto nos meses de junho, julho e agosto (para $\mathrm{pH}$ : anterior: 6,6 e posterior: 6,9; para sólidos dissolvidos totais, anterior: $\mathrm{Mdn}=35,0 \mathrm{mg} / \mathrm{l}$ e posterior: $\mathrm{Mdn}=48,5 \mathrm{mg} / \mathrm{l}$; para ferro total, anterior: $\mathrm{Mdn}=0,68 \mathrm{mg} / \mathrm{l}$ e posterior: $\mathrm{Mdn}=0,74 \mathrm{mg} / \mathrm{l})$. O número limitado de campanhas de monitoramento anterior à implantação do empreendimento provavelmente limitou a análise estatística para esses parâmetros.

Esses resultados corroboram com as comparações entre locais de coleta, uma vez que oferece evidências de que a implantação e operação das atividades de extração e beneficiamento do minério de ferro contribuiu para aumentar os níveis de diversos parâmetros de qualidade das águas dos rios e córregos localizados no entorno do empreendimento. 


\section{CONCLUSÕES}

A implantação e operação do empreendimento minerário denominado Sistema Minas-Rio contribuiu para aumentar as concentrações de $\mathrm{pH}$, sólidos dissolvidos totais, sólidos suspensos totais, turbidez, ferro total e manganês total nos corpos hídricos adjacentes, localizados na sub-bacia hidrográfica do Córrego Passa Sete. O aumento desses parâmetros está relacionado principalmente ao aumento dos processos erosivos durante a fase de instalação do empreendimento, quando a remoção de vegetação, escavações e obras contribuíram para o aporte de material (solo) para os corpos hídricos da região.

A maioria dos parâmetros de qualidade de águas apresentou conformidade com a Resolução CONAMA no $357 / 05$ ao longo das campanhas de monitoramento, com alguns picos extrapolando os limites sobretudo para os parâmetros turbidez, manganês total, DBO e coliformes termotolerantes. Estes resultados sugerem a não adequação da qualidade das águas da região aos seus diversos usos, sobretudo aqueles relacionados a abastecimento doméstico, dessedentação de animais e recreação de contato primário.

\section{REFERÊNCIAS}

ASSOCIAÇÃO BRASILEIRA DE NORMAS TÉCNICAS. NBR 9897. Planejamento de amostragem de efluentes líquidos e corpos receptores. Rio de Janeiro, junho de 1987a.

ASSOCIAÇÃO BRASILEIRA DE NORMAS TÉCNICAS. NBR 9898. Preservação e técnicas de amostragem de efluentes líquidos e corpos receptores. Rio de Janeiro, junho de 1987b.

AMERICAN PUBLIC HEALTH ASSOCIATION. Standard Methods for the Examination of Water and Wastewater, $23^{\text {rd }}$ edition. 2017.

BRANDT MEIO AMBIENTE. Estudo de Impacto Ambiental: Lavra a Céu Aberto para Produção de 56 Milhões de Toneladas por Ano, Tratamento de Minério de Ferro e Infra-Estrutura de Produção. MMX - Minas-Rio Mineração e Logística LTDA. Setembro, 2007.

BRASIL. Conselho Nacional de Meio Ambiente (CONAMA). Resolução $\mathbf{n}^{\circ}$ 357, de 17 de março de 2005. Brasília, DOU de 18/03/2005.

COSTA, A. T.; NALINI, H. A.; LENA J. C.; FRIESE, K.; MAGES, M. Surface water quality and sediment geochemistry in the Gualaxo do Norte basin, eastern Quadrilátero Ferrífero, Minas Gerais, Brazil. Environmental Geology, v. 45, p. 226-235, 2003.

FERREIRA ROCHA. Estudo de Impacto Ambiental: Projeto de Otimização da Mina do Sapo. Anglo American Minério de Ferro Brasil S/A. Belo Horizonte: Novembro, 2014. 
FERREIRA ROCHA. Estudo de Impacto Ambiental: Projeto de Extensão da Mina do Sapo. Anglo American Minério de Ferro Brasil S/A. Belo Horizonte: Setembro, 2015.

GALHARDI, J. A.; SOLDERA, B. C. Efeitos da drenagem ácida de mina sobre a qualidade das águas subterrâneas: preceitos legais e técnicos. Holos Environment, v. 18, n. 1, p. 87$109,2018$.

GODINHO, C.P.; VIANA, E. M.; SANTA ROSA, H; ZHOURI, A. Conflitos ambientais e as contradições do desenvolvimento sustentável: o caso da Mineração em Conceição do Mato Dentro/MG e suas consequências. In: ENCONTRO NACIONAL DE ESTUDOS POPULACIONAIS (ABEP), XX., 2016, Foz do Iguaçu. Anais... Foz do Iguaçu: 2016.

GUEDES, J. Exploração de minério de ferro em Conceição do Mato Dentro (MG) afeta meio social e ambiente. In: FERNANDES, F. R. C.; ALAMINO, R. C. J.; ARAUJO, E. R. (Eds). Recursos Minerais e Comunidade: impactos humanos, socioambientais e econômicos. Rio de Janeiro, CETEM/MCTI, 2014. p. 249-252. Disponível em: <http://www.cetem.gov.br/livros>

GUIMARÃES, L.C.; MILANEZ, B. Mineração, impactos locais e os desafios da diversificação: revisitando Itabira. Desenvolvimento e Meio Ambiente, v. 41, p. 215-236, 2017.

INSTITUTO BRASILEIRO DE MINERAÇÃO. Panorama da Mineração em Minas Gerais. Instituto Brasileiro de Mineração, Sindicato Nacional da Indústria da Extração do Ferro de Metais. Brasília: $\quad$ IBRAM, $2015 . \quad$ Disponível em <http://www.ibram.org.br/sites/1300/1382/00006212.pdf> Acesso em: abr. 2018.

KATPATAL, Y. B.; PATIL, S. A.; SINGH, C. K. Estimation of Sediment Yield within Mining Watershed to Assess Impact of Mine Dumps Using Satellite Data: Modified Approach. Journal of Environmental Engineering, v._143, n. 10, p. 1-11, 2017.

KRISHNASWAMY, J.; BUNYAN, M.; MEHTA, V. K.; JAIN, N.; KARANTH, K.U. Impact of iron ore mining on suspended sediment response in a tropical catchment in Kudremukh, Western Ghats, India. Forest Ecology and Management, v. 224, n. 1-2, p. 187-198. 2006.

LOPES C.; RUCHKYS. U. Recursos da geodiversidade de São Thomé das Letras - MG e seu uso para mineração e geoconservação: perspectivas para a reconversão desse território mineiro. Desenvolvimento e Meio Ambiente, v. 35, p. 335-347, 2015.

MDGEO - Serviços de Hidrogeologia Ltda. Relatório Anual das Atividades Realizadas de Janeiro a Dezembro de 2015. Projeto de Otimização da Mina do Sapo. Processo $\mathrm{N}^{\circ}$ 00472/2007/007/2014. Belo Horizonte, Março de 2017.

MECHI, A.; SANCHES, D. J. Impactos ambientais da mineração no Estado de São Paulo. Estudos Avançados, v. 24, n. 68, p. 209-220, 2010.

PEREIRA, A. A.; MENDONÇA, A. S. F.; ANDRADE FILHO, M. C. Aspectos Qualitativos de Águas de Lagoas Costeiras e seus Fatores Influentes - Estudo de Caso: Lagoa Mãe-Bá, Espírito Santo. RBRH - Revista Brasileira de Recursos Hídricos, v. 11, n. 1, p. 63-77, 2006.

PEREIRA, A. A.; VAN HATTUM, B.; BROUWER, A.; VAN BODEGOM, P.M.; REZENDE, C. E.; SALOMONS, W. Effects of iron-ore mining and processing on metal bioavailability in a tropical coastal lagoon. Journal of Soils Sediments, v. 8, p. 239-252, 2008. 
PEREIRA, D. C.; BECKER, L.C.; WILDHAGEN, R. O. Comunidades atingidas por mineração e violação dos direitos humanos: cenários em Conceição do Mato Dentro. Revista Ética e Filosofia Política, v. 16, n. 1, p. 124-150, 2013.

PEREIRA, D. C.; GUIMARÃES, L. O.; GUERRA, P. G. T.; GENTIL, P. P. C.; SIFFERT, P. V. Irresponsabilidades organizacionais ou ausência de governança territorial? Reflexões sobre gestão ambiental no Projeto Minas-Rio. In: CONGRESSO INTERNACIONAL RESAG, 3., 2017, Belo Horizonte. Anais... Belo Horizonte: 2017.

PIMENTEL, D. A.; RUSSO, J. F. C.; MAZZINGHY, D. B.; TURRER, H. D. G. Efeito da granulometria e da dosagem de amina na flotação de itabiritos. Holos, v. 30, n. 4, p. 118-125, 2014.

RODRIGUES, A. S. L; MALAFALIA, G; COSTA, A. T.; NALINI JÚNIOR, H. A. Iron ore mining promotes iron enrichment in sediments of the Gualaxo River Basin, Minas Gerais State, Brazil. Environmental Earth Science, v. 71, n. 7, p. 4177-4186, 2014.

SALOMONS, W. Environmental impact of metals derived from mining activities: processes, predictions, prevention. Journal of Geochemical Exploration, v. 52, n. 1-2, p. 5-23, 1995.

SEBASTIAN, T.; NATH, B. N.; NAIK, S.; BOROLE, D. V.; PIERRE, S.; YAZING, A. K. Offshore sediments record the history of onshore iron ore mining in Goa State, India. Marine Pollution Bulletin, v. 114, n. 2, p. 805-815, 2017.

SILVA, M. L.; ANDRADE, M. C. K. Os impactos ambientais da atividade mineradora. Caderno Meio Ambiente e Sustentabilidade, v. 11, n. 6, p. 67-82. 2017. Disponível em: $<$ https://www.uninter.com/cadernosuninter/index.php/meioAmbiente/article/view/541>

UNITED STATES ENVIRONMENTAL PROTECTION AGENCY. Data Quality Assessment: Statistical Methods for Practitioners. Washington: Office of Environmental Information, 2006. Disponível em <https://nepis.epa.gov/Exe/ZyPURL.cgi?Dockey=900B0D00.TXT> Acesso em mai. 2018.

VON SPERLING, E.; JARDIM, F. A.; GRANDCHAMP, C. A. P. Qualidade da água durante a formação de lagos profundos em cavas de mineração: estudo de caso do lago de Águas Claras - MG. Engenharia Sanitária e Ambiental, v. 9, n. 3, p. 250-259, 2004.

VON SPERLING, M. Introdução à qualidade das águas e ao tratamento de esgotos. Belo Horizonte: Editora UFMG, 4. ed., 2014.

WINDMOLLER, C. C.; SANTOS, R.C.; ATHAYDE, M.; PALMIERI, H. E. L. Distribution and speciation of mercury in sediments from gold mining sites in iron quadrangle (Minas Gerais). Química Nova, v. 30, n. 5, p. 1088-1094, 2007. 